\title{
King's Fund Forum \\ Screening for Fetal and Genetic Abnormality \\ The need for a British Association for Genetic Medicine
}

The King's Fund is an independent body, originally endowed by King Edward VII to help London hospitals, but now with a much wider range of interests in the Health Service. One of these is to organise consensus development conferences as initiated in the United States of America at the National Institutes of Health. These take a specific medical technology or procedure and assess its application in health care. A unique feature of the process is that a panel, from a broad range of backgrounds, listens to the evidence presented by experts and to views from the audience and prepares answers to a set of questions about the technology or procedure. The conference is open to the public to participate with the professionals in this process.

The Fourth King's Fund forum was held in London from 30 November to 2 December 1987 and considered questions related to screening for fetal and genetic abnormality. This recognised the general growth in interest resulting from the progressive decline in importance of other causes of disability, the astounding progress of molecular genetics, and the Health for All initiative by the World Health Organization which has included a focus on disabled people. The questions asked were: what kinds of tests are possible? what are their benefits and costs? what social and ethical issues arise? what criteria should be considered for the provision of these screening programmes, and how should they be organised and monitored? A panel of 12 (including one medical geneticist) listened to evidence from experts in public sessions attended by 250 people including professionals from many disciplines as well as the public and press (medical geneticists, although represented, were very much in a minority and could not be said to have exerted undue influence). After closed sessions the panel discussed their report with the audience and the panel's consensus statement was then presented at a press conference. The statement, admirably reflecting the mood of the public sessions, was overwhelmingly in favour of the rapid development of screening and was published in full in the British Medical Journal two weeks later (1987;292:1551-3): copies are available on request from The King's Fund, 126 Albert Street, London NW1 7NF.

Several invited lay speakers with personal experience of genetic disorders (in their own families or through patient organisations) criticised what they saw as a lack of genetic counselling and said that doctors and services often failed to communicate effectively. Women were sometimes left in doubt about the results of prenatal screening, diagnosis of genetic disorders, prognosis, and implications for other family members. The panel however noted the success of regional genetic centres (where they existed) in providing specialist genetic counsellors, an effective database, a genetic register, and a DNA bank. In most regions there is at least the core of a genetic service, including chromosome laboratories, and there is some evidence of progress: more consultant and training posts, active cytogenetic quality assessment schemes, favourable reports from the Departments of Health on centrally funded DNA work, modest local funding for DNA work in some regions, and, most importantly, the certainty that the integrated regional genetic centre provides efficiently the type and quality of service that the families need and increasingly demand.

A plea from sickle cell screening workers for greater collaboration from genetic centres allowed discussion of the disproportionate size of the task given the current total in the UK of only 30 or so consultant clinical geneticists and underfunded laboratories. This scarcity of medical genetics is a serious problem which will affect many aspects of hospital and community services as the number of genetic disorders suitable for this approach increases. The need was agreed for public education, more undergraduate and postgraduate training in genetics, and generally more comprehensive genetic services throughout Britain.

The panel comprised: J Grimley Evans (Chairman), Eva Alberman. Ruth Ashton, Martin Bobrow, Peter Coe, Anthony Culyer, Marion Hall, Roger Higgs, Marianne Rigge. Hilary Rose. Alwyn Smith, and Albert Weale. Invited experts presenting evidence were: Ms E Anionwu. Professor D Brock. Dr H Cuckle, Professor G Dunstan. Professor M Ferguson-Smith. Dr A Harding. Professor R Harris. Mr J Henderson. Professor B Hibbard, Mrs C Lavery, Dr S Macintyre. Ms M McTair. Dr B Modell. Dr M Pembrey. Dr M Richards. Professor C Rodeck. Mr S Thomas. Professor N Wald. and Professor Sir David Weatherall. 
The panel, in stating that new Health Service money was required to achieve these objects, recognised that competition for resources was fierce and genetic services had to be seen to give good value for money. While the importance was recognised of prevention when evaluating the costs and benefits of screening, this was not the only, nor even the greatest, benefit. Very large numbers of relatives can be given vital information to help them plan their lives and reproduction and many experience the relief from lifelong anxiety that negative carrier tests can bring. The King's Fund statement recommended that one should:

“... account imaginatively and comprehensively for all relevant factors ... (because) ... if only monetary information is considered there is a danger that the quantified may drive out the important in a kind of Gresham's law of screening".

In relation to the question on ethics, the need was agreed for confidentiality, informed consent, and equitable provision of services while society may wish to place limits on the types of conditions for which to provide screening. It was recognised, however, that there was no consensus regarding the "rights of the fetus". Personal views were to be respected but the King's Fund statement concluded that ...

"There is evidence that a conscientious objection to abortion on the grounds of fetal abnormality is the view of only a minority in our society."

In answering the question relating to the organisation of screening services the panel noted the pace of DNA technical development which will certainly lead to different, simpler, and more widely applicable screening procedures and commented ...

"Once decisions have been made about the screening procedures to be offered it will be possible to decide which aspects of the screening programme require to be associated with a specialised clinical genetic service and which can satisfactorily be carried out by hospital and community obstetric services. Basic pregnancy screening is best carried out as part of normal antenatal care".

What should the medical genetics community learn from this crucial consensus meeting with its support of genetic centres and overwhelming vote of confidence in screening, carrier detection, counselling, and a firm endorsement of selective termination as an option up to 24 weeks? There is certainly no justification for complacency because problems abound. There are powerful forces opposed to abortion (particularly after 18 weeks) although they were not much in evidence at this public and well publicised meeting. In any case funds must be found for research to achieve primary prevention, and perhaps preimplantation diagnosis, and so reduce the need for abortion. There are far too few medical geneticists (including clinicians and scientists) to develop on their own all the possibilities of genetic medicine and there is certainly no other group with adequate genetic training. The King's Fund statement pointed the way forwards ...

"The complexity of these issues suggests a need for planning and coordination at national level with a $₹$ remit to see that the good quality services at present deployed in some regions should be available $\bigcirc$ throughout the country. Services should be able to respond appropriately to the opportunities to be expected from the new genetic technologies."

Genetic centres have begun to achieve internally the degree of interdisciplinary harmony essential for the $\odot$ new genetics, but rare in the hierarchical world of clinical medicine. This tender plant must be nurtured because a united service will be more efficient and will have no difficulty attracting and collaborating with a rich assortment of clinicians, scientists, and other health care workers who will be drawn into the common purpose of management of genetic problems and will be grateful for the specialist support of the genetic centre.

The time is now ripe to establish a planning forum to reflect nationally the philosophy of the successful $\stackrel{\mathscr{D}}{?}$ multidisciplinary regional genetic services. The founding partners would include the Association of Clinical Cytogeneticists, the Clinical Genetics Society, the Clinical Molecular Geneticists, and others who will be active in this field. A British Association for Genetic Medicine when advising DHSS would speak with authority and could do much to guarantee effective and efficient genetic services into the 21 st century.

RODNEY HARRIS 